\title{
Theoretical Biology
}

National Cancer Institute

\section{Source}

National Cancer Institute. Theoretical Biology. NCI Thesaurus. Code C19061.

A field of biology that uses models and existing data and observations to explain some aspect of the biological world. The emphasis is on the production of ideas rather than data. 